\title{
EFEKTIVITAS PENERAPAN MEDIA PEMBELAJARAN INTERAKTIF BERBASIS GOOGLE CLASSROOM DALAM MENYONGSONG ERA REVOLUSI INDUSTRI 4.0 TERHADAP HASIL BELAJAR MATEMATIKA SISWA
}

\author{
Ropinus Sidabutar \\ Universitas HKBP Nommensen Pematangsiantar, Indonesia. \\ Email: regarstar.jd89@gmail.com
}

\begin{abstract}
Various technologies are used in optimizing student learning outcomes in the world of education. There are several interactive applications that teachers and students can use to learn mathematics. One of them is the use of google classroom. The use of Google Classroom can create virtual classes. The purpose of this study is to determine the effectiveness of the application of interactive learning media based on google classroom in welcoming the industrial revolution 4.0 era on the mathematics learning outcomes of class XI students. This research is an experimental non-equivalent control group design. The results of this study indicate that there is a difference in the average learning outcomes of mathematics in students who are taught without the application of learning media based on Google Classroom and classes taught with the application of interactive learning media based on Google Classroom. In addition, the use of google classroom-based learning is more effectively applied to improve mathematics learning outcomes for class XI students compared to learning without using google classroom-based learning media.
\end{abstract}

Keywords: Google Classroom, Mathematics Learning Outcomes, Interactive Media

\begin{abstract}
ABSTRAK
Berbagai teknologi dipakai dalam mengoptimalkan hasil belajar peserta didik dalam dunia pendidikan. Ada beberapa aplikasi bersifat interaktif yang bisa dipergunakan guru dan juga para peserta didik untuk belajar matematika. Salah satunya yaitu penggunaan google classroom. Pemanfaatan goolge classroom ini dapat membuat kelas maya. Tujuan dari penelitian ini yaitu untuk mengetahui efektifitas penerapan media pembelajaran interaktif berbasis google classroom dalam menyongsong era revolusi industri 4.0 terhadap hasil belajar matematika siswa kelas XI. Penelitian ini bersifat eksperimen non-equivalent control group desain. Hasil dari penelitian ini menunjukkan bahwa ada perbedaan rata-rata hasil belajar matematika pada siswa yang diajar tanpa penerapan media pembelajaran berbasis goolge classroom dan kelas yang diajar dengan penerapan media pembelajaran interaktif berbasis goolge classroom. Disamping itu, penggunaan pembelajaran berbasis google classroom lebih efektif diterapkan untuk meningkatkan hasil belajar matematika siswa kelas XI dibanding pembelajaran tanpa menggunakan media pembelajaran berbasis google classroom.
\end{abstract}

Kata Kunci: Google Classroom, Hasil Belajar Matematika, Media Interaktif

\section{PENDAHULUAN}

Pendidikan 4.0 adalah istilah yang digunakan para ahli dalam teori pendidikan untuk mendeskripsikan berbagai cara untuk mengintegrasikan teknologi baik secara fisik maupun tidak ke dalam pembelajaran. Saat ini pendidikan mulai berbenah diri dalam peningkatan kualitas melalui Revolusi Industri 4.0. Ada banyak pelatihan yang membahas pendidikan 4.0. Akan tetapi pada kenyataannya masih banyak guru yang kesulitan dalam menggunakan teknologi guna menunjang pembelajaran. Sangat dibutuhkan keselarasan antara manusia dan teknologi informasi dalam pendidikan 4.0 untuk menemukan solusi dalam memecahkan berbagai masalah yang timbul dan juga menciptakan peluang yang bersifat kreatif serta inovatif dalam memperbaiki sektor kehidupan. Dalam hal ini guru diharuskan agar mau tidak mau mempelajari teknologi 
guna mentransferkan ilmunya melalui Kegiatan Belajar Mengajar (KBM) secara online.

Karakteristik era rovolusi industri 4.0 yaitu perkembangan teknologi yang luar biasa terutama pada bidang industri. Dalam perkembangan bidang industri berdampak pada berkurangnya tenaga manusia yang akan digantikan oleh teknologi mesin seperti tenaga mesin bahkan robot-robot pintar. Hal ini mebuat manusia dituntut untuk lebih kreatif agar dapat menciptakan lapangan kerja baru. Oleh sebab itu, peningkatan sumber daya manusia dapat mengungguli mesin-mesin canggih yang notabene adalah buatan manusia. Peningkatkan SDM (sumber daya manusia) tidak terlepas dari peranan pendidikan sebagai pemikul amanat UUD 1945 yaitu mencerdaskan kehidupan bangsa (Widiansyah, 2018).

Dalam meningkatkan kualitas SDM untuk menyongsong era industri 4.0 maka perlu diperkenalkan dunia IT mulai dari pendidikan dasar sampai ke pendidikan tinggi. Hal ini memberi tantangan kepada dunia pendidikan agar dapat membuat rangkaian pembelajaran yang dekat dengan kegiatan peserta didik di media social (Hatip \& Listiana, 2019). Di era milenial sekarang ini menggunakan teknologi sebagai transformasi pembelajaran offline ke online (Kadir, 2020). Dari berbagai macam pembelajaran e learning, google classroom menjadi salah satu aplikasi yang banyak digunakan dalam menyelenggarakan pendidikan. Google classroom atau google kelas merupakan aplikasi pembelajaran daring berbasis web yang dibuat untuk mempermudah kegiatan pembelajaran antara pengajar dengan siswa tanpa harus bertatap muka secara langsung. Pemanfaatan aplikasi E-learning berbasis google classroom sebagai media dalam pembelajaran mempermudah guru-guru dalam pengarsipan dan pengorganisasian berkas tugas dan proses penilaian (Mu'minah, 2020). Penggunaan dari Google classroom sangat fleksibel, mudah di akses dimana saja dan kapan saja, terkendala akses internet dari tidak adanya jaringan data maupun smartphone yang digunakan sebagai pendukung semua siswa untuk pelaksanaan pembelajaran e-learning (Atikah, 2021).

Aplikasi Google untuk Pendidikan dengan memberikan pelatihan dengan target guru untuk peningkatan knowledge dan skill dalam pembelajaran secara online (Novalia, 2018). Tujuan dengan pemaparan dengan memberikan pelatihan dalam menggunakan Classroom dengan Google. Adanya permohonan dari peserta untuk follow up setelah pelatihan yang dapat mewujudkan tujuan tersebut (Kurniawan, dkk., 2020). Pendekatan kualitatif adalah cara yang dilakukan dalam pengabdian ini. Peserta dalam pelatihan dapat membuat content yang berhubungan dengan education dan diunggah pada YouTube (Chusyairi A. \& Sabira S., 2020). Pemberian pengetahuan dan pelatihan kepada peserta dengan classroom untuk memudahkan dalam pembelaran merupakan tujuan dari pengabdian. Media ceramah, tanya jawab, dan langsung demonstrasi dengan classrom adalah metode yang ada dalam pengabdian (Malalina \& Yenni R. F., 2018). Pelatihan elearning dengan Classroom meliputi tahap: a) persiapan, melakukan penggalian terhadap masalah mengenai elearning dengan penyajian materi, b) pelaksanaan, pelatihan dalam menggunakan Classroom, dan c) evaluasi, hambatan yang ada ketika pelatihan (Novian, 2019). Classroom adalah tool dalam pembelajaran berbasis web dari Google. Berkaitan dengan pembelajaran berbasis google classroom, ditemukan beberapa permasalahan, yaitu: 1) Guru tidak mengetahui konsep-konsep pembelajaran berbasis web, 2) Guru tidak memiliki pengetahuan dan keterampilan dalam mendisain pembelajaran berbasis google classroom, 3) Guru belum mengetahui bagaimana cara membuat kelas berbasis google classroom dan belum tahu cara mengelola kelas berbasis google classroom, 4) 
Ketiadaan sumber daya manusia yang menguasai konsep pembelajaran berbasis google classroom dan penerapannya yang dapat mendampingi (Palennari, 2019).

Dari hasil wawancara dengan guru SMA Padamu Negeri menyimpulkan bahwa diperlukan penerapan media yang lebih baik supaya siswa semangat dalam belajar, fokus, dan juga tidak membosankan pembelajaran. Sehingga proses pembelajaran terkhusus matematika dengan menerapkan sistem e-learning menjadi fokus peneliti. Hasil belajar dengan kegiatan pembelajaran memiliki keterkaitan yang erat. Menurut Hamdani dalam Karina, Syafrina, \& Habibah, perubahan watak peserta didik sesudah menyelesaikan kegiatan pembelajaran (Karina dkk., 2017). Brigg dalam Mansur mengungkapkan hasil belajar adalah semua keterampilan serta pencapaian yang diperoleh dari belajar menggajar ditentukan oleh angka-angka sebagai hasil pengukuran tes keberhasilan belajar (Mansur, 2015). Menurut Susanto dalam Karina, Syafrina, \& Habibah, hasil belajar yaitu apa yang dicapai peserta didik sesudah belajar (Karina dkk., 2017). Berdasarkan beberapa pendapat, didapat kesimpulan bahwa hasil pembelajaran merupakan perubahan yang diperoleh anak sebagai bentuk pencapaian dari semua proses pembelajaran berdasarkan tujuan belajar yang ditetapkan. Sehingga, hasil belajar matematika yaitu nilai kognitif pencapaian anak dari hasil belajar pada kompetensi dasar tertentu. Banyak sebab yang mempengaruhi hasil belajar yaitu sebab internal maupun eksternal individu. Munadi dalam Najikhah, Budiyono, \& Wardi menyatakan bahwa faktor yang memengaruhi usaha peserta didik dalam mencapai hasil pembelajaran adalah: (1) sebab yang muncul dalam diri peserta didik (internal factor), seperti kurangnya keinginan belajar, ia terbiasa ditaman kanak-kanak lebih senang bermain-main disekolah dan (2) sebab lain muncul dari luar diri (external factor), seperti pendekatan pembelajaran, yaitu cara guru mengajar serta model, metode, sarana, atau pembelajaran yang digunakan (Najikhah dkk., 2016. Dari uraian tersebut, peneliti ingin melakukan penelitian untuk melihat efektifias penerapan media pembelajaran yang berbasis google classroom terutama dari segi pencapaian belajar agar mempersiapkan generasi masa yang akan datang dalam menyongsong era digital 4.0.

\section{METODE PENELITIAN}

Penelitian ini diadaptasi dari alur penelitian eksperimen yaitu berupa kuasi ekperimen dan mengaplikasikan desain non-equivalent control design dengan memiliki ciri khas kelas ekperimen ataupun kelas kontrol yang tidak dipilih secara acak akan tetapi berdasarkan atas pertimbangan tertentu. Lokasi penelitian dilaksanakan di SMA swasta Padamu Negeri dengan populasi yaitu kelas XI, dan sampelnya berasal dari kelas XI IPA 1 dan 2. Teknik yang digunakan dalam menganalisa data yaitumenggunakan analsiis deskriptif serta inferensial mengggunakan SPPS versi 21, dimana sebelumnya dilakukan uji prasyarat untuk melihat normalitas dan homegenitas dari pretest dan juga posttest serta independent samples t-test dalam pengujian hipotesis.

Untuk mengetahui ada tidaknya perbedaan dari pencapaian pembelajaran peserta siswa tanpa penerapan pembelajaran interaktif menggunakan google classroom dan peserta didik belajar dengan penerapan media pembelajaran menggunakan google classroom. Cara untuk melihat efektifitas pembelajaran dengan menggunakan pembelajaran interaktif berbasis google classroom dan tanpa menggunakan media pembelajaran berbasis google classroom menggunakan rumus efesiensi relatif. Instrumen yang digunakan telah divalidasi oleh pakar yang sesuai dengan disiplin ilmu. Instrumen tersebut disesuaikan dengan perangkat pembelajaran yang digunakan 
disekolah tersebut.

\section{HASIL DAN PEMBAHASAN PENELITIAN}

Hasil Deskripsi hasil pembelajaran matematika siswa dari XI IPA 2 yang mengaplikasikan pembelajaran tanpa menggunakan media interaktif berbasis google classroom yaitu:

Tabel 1. Hasil Pretest dan Posttest Kelas control

\begin{tabular}{lcc}
\hline Statistik & \multicolumn{2}{c}{ Nilai statisik kelas XI IPA 2 } \\
\cline { 2 - 3 } & Pretest & Posttest \\
\hline Banyak sampel & 25 & 25 \\
\hline Nilai terendah & 20 & 80 \\
\hline Nilai Tertinggi & 50 & 95 \\
\hline
\end{tabular}

Hasil dari analisis statistik dalam pretest kelas kontrol yang diajar tanpa penerapan media pembelajaran yang interaktif berbasis google classroom sebagai berikut:

Tabel 2. Analisis Statistik Deskriptif Pretest Kelas control

\begin{tabular}{lcccccc}
\hline & N & Minimal & Maksimal & Rerata & Std. Deviasi & Varians \\
\hline Pretest & 25 & 20,00 & 50,00 & 32,15 & 8,65 & 67,13 \\
\hline Valid N & 25 & \multicolumn{7}{c}{} & & \\
\hline
\end{tabular}

Hasil analisis statistik deskriptif posttest untuk kelas kontrol tanpa mengaplikasikan media pembelajaran interaktif google classroom.

Tabel 3. Analisis statistik Deskriptif Posttest Kelas Kontrol

\begin{tabular}{lcccccc}
\hline & N & Minimal & Maksimal & Rerata & Std. Deviasi & Varians \\
\hline Pretest & 25 & 80,00 & 95,00 & 84,50 & 6,65 & 41,25 \\
\hline Valid N & 25 & & & & & \\
\hline
\end{tabular}

Berikut nilai dari statistic deskriptif untuk perolehan tes awal sekaligus tes akhir pada kelas kontrol yang belajar tanpa mengaplikasikan media interaktif berbasis google classroom

Tabel 4. Nilai Statistik Deskriptif Pretest Dan Posttest Kelas Kontrol

\begin{tabular}{lcc}
\hline \multicolumn{1}{c}{ Statistik } & \multicolumn{2}{c}{ Nilai Statistik } \\
\cline { 2 - 3 } & Pretest & Posttest \\
\hline Nilai Terendah & 20,00 & 80,00 \\
\hline Nilai Tertinggi & 50,00 & 95,00 \\
\hline Rerata & 32,15 & 84,50 \\
\hline Standar Deviasi (SD) & 8,65 & 6,65 \\
\hline
\end{tabular}

Apabila hasil yang diperoleh peserta didik pada kelas kontrol yaitu pembelajaran tanpa penerapan media pembelajaran berbasis google classroom diklasifikasikan ke dalam 5 pengkategorian, maka didapatkan frekuensi juga persentase seperti berikut: 
Tabel 5. Distribusi Frekuensi dan Persentasi Skor Hasil Belajar Peserta didik Kelas Kontrol

\begin{tabular}{cccccc}
\hline Interval & Kategori & \multicolumn{2}{c}{ Pretest } & \multicolumn{2}{c}{ Posttest } \\
\cline { 3 - 6 } & & F & $\begin{array}{c}\text { Persentase } \\
\text { \% }\end{array}$ & F & $\begin{array}{c}\text { Persentase } \\
\boldsymbol{\%}\end{array}$ \\
\hline $0-54$ & Sangat rendah & 25 & 100 & 0 & 0 \\
\hline $55-64$ & Rendah & 0 & 0 & 0 & 0 \\
\hline $65-79$ & Sedang & 0 & 0 & 5 & 17 \\
\hline $80-89$ & Tinggi & 0 & 0 & 15 & 52 \\
\hline $90-100$ & Sangat tinggi & 0 & 0 & 5 & 31 \\
\hline
\end{tabular}

Deskripsi untuk hasil pembelajaran matematika pada peserta didik dalam kelas eksperimen XI IPA 1 yang belajar dengan penerapan media pembelajaran interaktif berbasis google classroom yaitu:

Tabel 6. Hasil Pretest dan Posttest Kelas Eksperimen

\begin{tabular}{lcc}
\hline \multicolumn{1}{c}{ Statistik } & \multicolumn{2}{c}{ Nilai statisik kelas XI IPA 1 } \\
\cline { 2 - 3 } & Pretest & Posttest \\
\hline Banyak sampel & 24 & 24 \\
\hline Nilai terendah & 25 & 85 \\
\hline Nilai Tertinggi & 55 & 100 \\
\hline
\end{tabular}

Dari data analisis statistik deskriptif pretest untuk kelas eksperimen yang mengaplikasikan media pembelajaran berbasis google classroom adalah:

Tabel 7. Hasil Analisis Statistik Deskriptif Pretest Kelas Eksperimen

\begin{tabular}{lcccccc}
\hline & N & Minimal & Maksimal & Rerata & Std. Deviasi & Varians \\
\hline Pretest & 24 & 25,00 & 55,00 & 27,68 & 8,12 & 64,74 \\
\hline Valid N & 24 & \multicolumn{5}{c}{} \\
\hline
\end{tabular}

Hasil analisis statistik deskriptif posttest kelas eksperimen dengan penerapan media pembelajaran interaktif berbasis google classroom yaitu:

Tabel 8. Hasil Analisis Statistik Deskriptif Posttest Kelas Eksperimen

\begin{tabular}{lcccccc}
\hline & N & Minimal & Maksimal & Rerata & Std. Deviasi & Varians \\
\hline Pretest & 25 & 85,00 & 100,00 & 90,10 & 6,12 & 30,14 \\
\hline Valid N & 25 & & & & & \\
\hline
\end{tabular}

Dari nilai dari statistik deskriptif pada hasil tes awal dan akhir untuk kelas eksperimen yang tidak mengaplikasikan media pembelajaran interaktif berbasis google classroom yaitu: 
Tabel 9. Nilai Statistik Deskriptif Pretest dan Posttest Kelas Eksperimen

\begin{tabular}{lcc}
\hline \multicolumn{1}{c}{ Statistik } & \multicolumn{2}{c}{ Nilai Statistik } \\
\cline { 2 - 3 } & Pretest & Posttest \\
\hline Nilai Terendah & 25,00 & 85,00 \\
\hline Nilai Tertinggi & 55,00 & 100,00 \\
\hline Rerata & 27,68 & 90,10 \\
\hline Standar Deviasi (SD) & 8,12 & 6,12 \\
\hline
\end{tabular}

Apabila hasil yang diperoleh peserta didik pada pembelajaran dengan pengaplikasian media pembelajaran berbasis google classroom diklasifikasikan ke dalam 5 kategori tertentu maka akan diperoleh frekuensi serta persentase seperti berikut:

\section{Tabel 10. Distribusi Frekuensi dan Persentasi Skor Hasil Belajar Peserta Didik Kelas Eksperimen}

\begin{tabular}{cccccc}
\hline Interval & Kategori & \multicolumn{2}{c}{ Pretest } & \multicolumn{2}{c}{ Posttest } \\
\cline { 3 - 6 } & & F & $\begin{array}{c}\text { Persentase } \\
\text { \% }\end{array}$ & F & $\begin{array}{c}\text { Persentase } \\
\boldsymbol{\%}\end{array}$ \\
\hline $0-54$ & Sangat rendah & 24 & 100 & 0 & 0 \\
\hline $55-64$ & Rendah & 0 & 0 & 0 & 0 \\
\hline $65-79$ & Sedang & 0 & 0 & 0 & 17 \\
\hline $80-89$ & Tinggi & 0 & 0 & 11 & 43 \\
\hline $90-100$ & Sangat tinggi & 0 & 0 & 13 & 57 \\
\hline
\end{tabular}

Untuk nilai rerata hasil belajar pretest dan posttest dalam kelas kontrol yang belajar tanpa penerapan media pembelajaran google classroom dan kelas eksperimen yang belajar dengan penerapan media pembelajaran google classroom disajikan dalam tabel di bawah:

Tabel 11. Rerata Pretest dan Posttest Kedua Kelas Sampel

\begin{tabular}{lcc}
\hline \multirow{2}{*}{ Kelas } & \multicolumn{2}{c}{ Nilai Rata-rata } \\
\cline { 2 - 3 } & Pretest & Posttest \\
\hline Konvensional & 25,47 & 86,45 \\
\hline Eksperimen & 26,68 & 90,38 \\
\hline
\end{tabular}

Dari tabel diatas dapat dilihat bahwa terdapat perbedaan rata-rata antara nilai yang diajar tanpa penerapan media pembelajaran interaktif berbasis google classroom dengan yang diajar dengan penerapan media pembelajaran interaktif berbasis google classroom. Untuk itu kelas yang diajar dengan penerapan media pembelajaran interaktif berbasis google classroom lebih efektif diterapkan dalam pembelajaran matematika dibandingkan tanpa penerapan media pembelajaran google classroom. Dengan mengambil taraf signifikan 0,05 , nilai sig yang didapatkan dari perhitungan SPSS ialah 0,035 sehingga dapat ditarik kesimpulan yaitu hipotesis pertama (H1) diterima sebab hasil sig < $\alpha$. Jadi, dapat disimpulkan bahwa ada perbedaan dari hasil belajar matematika peserta didik di SMA Padamu Negeri yang diajar tanpa penerapan media permbelajaran interaktif berbasis google classroom dan peserta didik yang 
diajar dengan penerapan media permbelajaran interaktif berbasis google classroom.

\section{Pembahasan}

Dari data analisis kelas kontrol yang diajar tanpa penerapan media pembelajaran berbasis google classroom dengan rata-rata nilai hasi pembelajaran matematika pada pretest yaitu 25,47 dan rata-rata pencapaian pembelajaran matematika pada posttest yaitu 86,45 . Pengkategorisasian nilai tertinggi pencapaian pembelajaran matematika peserta didik dalam pretest berada pada kategori rendah yaitu sebesar 25 orang dengan persentase $100 \%$. Sementara saat posttest nilai tertinggi ada pada kategori yang tinggi sebesar 15 orang dengan persentase 52\%. Dapat disimpulkan bahwa ada terdapat kenaikan nilai pencapaian pembelajaran matematika peserta didik sebelum dan setelah diterapkan pembelajaran tanpa menerapkan media pembelajaran interaktif google classroom. Dari data analisis yang diperoleh pada kelas eksperimen dengan penerapan media pembelajaran berbasis google classroom didapatkan nilai rerata pencapaian pembelajaran matematika pada pretest yaitu 26,68 dan nilai rata-rata pencapaian pembelajaran matematika pada posttest yaitu 90,38. Pengkategorisasian nilai tertinggi keahlian memecahkan permasalahan matematika peserta didik dalam pretest ada dalam kategori rendah yaitu sebesar 24 peserta didik dengan persentase $100 \%$ sedangkan pada posttest nilai tertinggi ada dalam kategori sangat tinggi sebesar 13 peserta didik dengan persentase 57\%. Dapat disimpulkan bahwa terdapat peningkatan signifikan terhadap pencapaian pembelajaran matematika peserta didik sebelum dan setela penerapan media pembelajaran interaktif google classroom. Dari hasil deskriptif tersebut, dapat melaksanakan pengujian prasyarat yakni normalitas dan homogenitas data sebelum dilakukan uji hipotesis pada nilai posttest pencapaian pembelajaran matematika pada kelas tanpa penerapan media pembelajaran interaktif google classroom dan kelas yang mengaplikasikan media pembelajaran interaktif google classroom dengan SPSS versi 20.

Hasil dari uji normalitas dan homogen posttest untuk kelas kontrol tanpa penerapan media pembelajaran interaktif berbasis google classroom dan kelas eksperimen dengan penerapan media pembelajaran interaktif berbasis google classroom menunjukkan bahwa nilai pembelajaran matematika peserta didik berasal dari kumpulan dengan distribusi normal dan homogen, hal ini dilihat dari skor signifikansi dalam kedua kelas yakni sebesar 0,645 dan 0,324. Skor signifikansi kelas eksperimen lebih dari 0,05 berarti sudah berdistribusi normal, sedangkan pada uji homogenitas diperoleh nilai sig $=0,670$, sehingga hasil posttest homogen karena nilainya lebih besar dari $\alpha$ : 0,05 . Setelah pengujian prasyarat sudah dipenuhi, peneliti selanjutnya menguji dugaan sementara (hipotesis) untuk mendapatkan jawaban dari ketiga rumusan masalah. Pengujian ini menggunakan independent sample t-test dan mendapat hasil skor sig $=0,035$, karena itu hipotesis pertama $(\mathrm{H} 1)$ diterima sebab skor $0,035<0,05$. Jadi ada perbedaan pada rerata hasil belajar matematika dari peserta didik Efektivitas Penerapan Media Pembelajaran Interaktif Berbasis google classroom dalam Menyongsong Era Revolusi Industri 4.0 terhadap Hasil Belajar Matematika yang tidak mengaplikasikan media dengan peserta didik yang mengaplikasikan media pembelajaran berbasis google classroom. Berdasarkan skor rerata hasil pembelajaran peserta didik untuk kelas tanpa mengaplikasikan media pembelajaran interaktif berbasis google classroom dan kelas yang belajar dengan penerapan media pembelajaran interaktif berbasis Google classroom bisa dikatakan skor yang didapatkan peserta didik yang mengaplikasikan media lebih meningkat dibanding yang tidak mengaplikasikan media. Hal ini karena media yang berbasis Google 
classroom membantu pihak guru dalam menggunakan kekuatan jejaring sosial dalam membentuk kelas virtual yang sesuai dengan kelas sebenarnya. Pada kelas ini ada materi pembelajaran, tugas, quiz, serta pemberian skor pada setiap akhir pembelajaran, sering juga dideskripsikan sebagai facebook untuk sekolah. Selain itu, google classroom ialah suatu situs khusus dibuat pendidik untuk membentuk kelas online. Situs ini tidak berbayar dan tidak sulit untuk dipakai selama perangkat terhubung ke internet. Dilakukan juga uji efektifitas untuk mengetahui keefektifan media pembelajaran interaktif berbasis google classroom.

Pembelajaran dengan penerapan media interaktif google classroom mengubah hasil belajar peserta didik lebih baik. Dengan penerapan pembelajaran ini peserta didik akan lebih bersemangat karena terkait dengan penerapan teknologi yang sebenarnya mereka telah terbiasa dalam penggunaan android, whatsapp dan facebook. Penelitian Pradja, Raisa, \& Jualeha menyimpulkan pembelajaran yang mengaplikasikan media elearning Google classroom memberikan pengaruh positif pada hasil belajar peserta didik (Pradja, dkk., 2019). Penelitian lain juga dilakukan oleh Surahman menyimpulkan bahwa pembelajaran dengan google classroom efektif digunakan dalam pembelajaran matematika. Penerapan media google classroom membuat pelajaran efektif, yang artinya berpengaruh dalam proses pembelajaran baik dari segi keaktifan maupun dari segi pencapaian tujuan pembelajaran (Surahman, 2019). Sementara itu, hasil penelitian Wardono, Waluya, Mariani, \& Safitri menyimpulkan bahwa kepiawaian dalam literasi matematika di kelas menerapkan model PBL pendekatan PMRI dibantu Google classroom telah meningkat dan peningkatan ini lebih tinggi dari pada kelas yang menggunakan model ekspositori. Penggunaan media interaktif yang disandingkan model pembelajaran akan berefek lebih positif terhadap kemampuan literasi matematika.

\section{PENUTUP}

Hasil dari paparan di atas, maka dapat disimpulkan bahwa terdapat perbedaan pada rerata hasil belajar peserta didik dalam belajar matematika antara kelas yang mengaplikasikan dan tidak mengaplikasikan media pembelajaran interaktif berbasis Google classroom. Hasil ini dapat dilihat dari hasil uji hipotesis independent sample ttest yang memperoleh nilai sig $=0,035<\alpha=0,05$, sehingga H1 diterima. Pembelajaran yang mengaplikasikan media pembelajaran interaktif berbasis Google classroom dinilai lebih efektif dalam meningkatkan hasil belajar dari peserta didik.

\section{DAFTAR PUSTAKA}

Atikah, dkk. (2021) Pemanfaatan Google Classroom Sebagai Media Pembelajaran Di Masa Pandemi Covid-19. Jurnal Teknologi dan Informasi.

Chusyairi, Ahmad, dkk. (2021). Pelatiahan Pembuatan Media Pembelajaran Jarak Jauh Dengan Google Classroom Di SMAN 15 KOTA BEKASI. Jurnal Pengabdian Kepada Masyarakat.

Karina, R. M., Syafrina, A., \& Habibah, S. (2017). Hubungan Antara Minat Belajar dengan Hasil Belajar Siswa dalam Mata Pelajaran IPA pada Kelas V SD Negeri Garot Geuceu Aceh Besar. Jurnal Ilmiah Pendidikan Guru Sekolah Dasar, 2(1), 61-77.

Kurniawan B., Purnomo A. \& Idris. (2020). Pelatihan Penggunaan Aplikasi Google Classroom sebagai Upaya Peningkatan Pembelajaran Online bagi Guru Matapelajaran IPS. International Journal of Community Service Learning. Malalina \& Yenni R. F. (2018). Pelatihan Google Classroom Untuk Mengoptimalisasi 
Proses Pembelajaran di FKIP Universitas Tamansiswa Palembang. Jurnal Cemerlang: Pengabdian pada Masyarakat, 1(1), 58-70.

Mansur, N. (2015). Pencapaian Hasil Belajar Ditinjau dari Sikap Belajar Mahasiswa. Lantanida Journal, 3(2), 107-115

Mayasari F., Dwita D., Jupendri, Hanafi N.K. \& Putra N.M. (2019). Pelatihan Komunikasi Efektif Media Pembelajaran Google Classroom Bagi Guru Man 2 Model Pekanbaru. Jurnal Pengabdian Untuk Mu NegeRI, 3(1), 18-23.

Najikhah, F., Budiyono, \& Wardi. (2016). Keefektifan MPI Game Edukasi terhadap Hasil Belajar IPA di Kelas 1 Sekolah Dasar. Indonesian Journal of Curriculum and Educational Technology Studies, 4(2), 58-65

Novian D. R. (2019). Optimalisasi Penggunaan Google Classroom sebagai Media ELearning bagi Mahasiswa Kedokteran Hewan Universitas Nusa 50

Novalia M., Ismanto E., Vitriani, Darni R., Alrian R. \& Herlandi P.B. (2018). Google Apps For Education (Gafe) Demi Peningkatan Kualitas Pembelajaran Era Digital Di SMK DAR-EL Hikmah Pekanbaru. Jurnal Pengabdian Untuk Mu NegeRI, 2(2), 7-11.

Surahman. (2019). Efektivitas Penggunaan Edmodo dalam Pembelajaran Matematika. https://www.researchgate.net/deref/http $\% 3 \mathrm{~A} \% 2 \mathrm{~F} \% 2 \mathrm{Fdx}$. doi.org\%2F10.13140\% 2FRG.2.2.25121 .04966

Wardono, Waluya, S. B., Mariani, S., \& Safitri, A. D. (2016). Mathematics Literacy on Problem Based Learning with Indonesian Realistic Mathematics Education Approach Assisted E-Learning Edmodo. Journal of Physics: Conference Series, 693(1), 1-10. 